\title{
CONHECIMENTO E DESENVOLVIMENTO PROFISSIONAL DE FORMADORES DE FUTUROS PROFESSORES
}

\author{
William Xavier de Almeida \\ Universidade do Estado de Santa Catarina - UDESC, Brasil \\ Adriana Richit \\ Universidade Federal da Fronteira Sul - UFFS, Brasil
}

\begin{abstract}
Resumo
$\mathrm{O}$ artigo discute os conhecimentos profissionais evidenciados por formadores de futuros professores, especificamente docentes de cursos de licenciatura, a partir de ações formativas promovidas pela instituição na qual atuam. $\mathrm{O}$ estudo, de natureza qualitativa-interpretativa e apoiado na perspectiva dos conhecimentos profissionais de Lee Shulman, envolveu a análise de documentos oficiais e institucionais relativos às políticas e ações de formação de formadores de professores, bem com a aplicação de questionário aos docentes das áreas de ciências humanas e sociais e realização de entrevista com quatro professores dentre aqueles que responderam ao questionário, os quais se disponibilizaram a conceder-nos entrevistas. Os participantes da pesquisa são docentes de cursos de licenciatura de uma universidade pública federal do sul do Brasil, fixada no estado de Santa Catarina. $\mathrm{O}$ estudo aponta que a participação dos formadores de futuros professores em diferentes ações formativas oportunizou-os desenvolver reflexões sobre aspectos relativos ao conhecimento didático, tais como abordagens de ensino, processos de avaliação e compreensão sobre as dificuldades dos alunos.
\end{abstract}

Palavras-chave: Conhecimento profissional; Desenvolvimento profissional; Ensino universitário; Formação de formadores de professores; Profissionalidade docente.

\begin{abstract}
The paper discusses the professional knowledge evidenced by teacher educators of prospective teachers, specifically of humanities' teacher education courses, as from formative activities promoted by their university. The research, which pursues the qualitative and interpretative nature and supported by the professional knowledge perspective of Lee Shulman, involved the analyses of official and institutional documents concerning to policies and activities of teacher education that teaching to prospective teacher. Furthermore, we applied questionnaires to teachers and conducted interviews with four teachers who accepted give us their statements. The research participants are from social sciences and humanities course teachers of the federal public university, located in the Santa Catarina state. The research pointed to participation of teachers in different formative activities provided them develop reflections about aspects relatives to didactic knowledge, such as teaching approach, evaluation processes and comprehensions relatives to student difficulties.
\end{abstract}

Keywords: Professional knowledge; Professional development; University teaching; Teacher education of prospective teacher; Teacher professionalism. 


\section{Introdução}

A docência, ou seja, o ato de ensinar, é o elemento principal que constitui a especificidade profissional do professor. Esta concepção tem sido relativamente estável ao longo do tempo, mesmo em face das mudanças que transformam as sociedades. Nesta perspectiva, o conceito de ensinar, enquanto processo socialmente construído e mutável (Roldão, 2007), estrutura-se a partir de alguns aspectos do ensino que são preservados ao longo do tempo, tais como a dinâmica subjacente ao trabalho em sala de aula, os quais atribuem identidade à profissão. Ou seja, transversalmente a épocas e a culturas, ensinar constitui-se como a mediação operada por alguém (docente) entre o conhecimento a ser adquirido (conteúdo, currículo) e o sujeito que aprende (aluno) (Roldão, 2014). Emerge, no cerne desta compreensão, a relevância do conhecimento profissional do professor, concebido como elemento central da prática e, portanto, da profissionalidade docente (Cunha e Zanchet, 2014; Bazzo, 2007; Cunha, 2005). Nesta perspectiva, os processos formativos vivenciados pelo professor ao longo da carreira precisam favorecer o desenvolvimento profissional, perpassando o desenvolvimento e o aprofundamento de distintos conhecimentos e mudanças na prática (Richit, 2020).

Estes aspectos evidenciam a relevância da discussão sobre os conhecimentos que compõem a profissionalidade docente, pois segundo Roldão (2014; 2007), ser professor não é dom ou vocação: é profissão apoiada e legitimada por um complexo corpo de conhecimentos específicos necessários à prática docente. Assim, entendemos o desenvolvimento profissional como um processo contínuo e dinâmico ao longo da trajetória do professor (Cunha e Zanchet, 2014; Bazzo, 2007; Zabalza, 2004; Ponte 1994), que não se encerra mediante determinada formação ou titulação, e que requer comprometimento com a melhoria da prática a partir de novos conhecimentos.

Zabalza (2004) acrescenta que no atual cenário educacional, a formação inicial desempenha papel importante, mas não exclusivo nem prioritário na formação profissional docente. A formação profissional docente inicia antes mesmo do aspirante a professor ingressar em um curso de licenciatura; se desenvolve dentro e fora de suas disciplinas e programas; e se amplia para outros percursos formativos realizados nas universidades (Cunha, 2005; Zabalza, 2004). Essa perspectiva é apontada por Zabalza (2004) ao destacar que já é comum nas universidades, pelo menos na Europa, haver mais estudantes frequentando cursos de pós-graduação do que de graduação.

Relativamente à discussão sobre os conhecimentos profissionais de professores, nos reportaremos às pesquisas do psicopedagogo norte-americano Lee Shulman, cujos trabalhos contribuíram para elucidar e categorizar os diferentes tipos de conhecimentos necessários à docência. A partir desta abordagem buscamos evidenciar e discutir os conhecimentos mobilizados nos processos de desenvolvimento profissional docente, mais especificamente, na formação continuada de formadores de futuros professores.

$\mathrm{Na}$ perspectiva de contribuir com as discussões sobre esta temática, nos dedicamos a investigar o desenvolvimento profissional de formadores de futuros professores, buscando evidenciar e discutir os conhecimentos profissionais privilegiados neste processo, e 
examinando-os no contexto das ações promovidas na Universidade Federal da Fronteira Sul - UFFS, uma universidade pública situada na região oeste de Santa Catarina.

A investigação foi orientada pela seguinte problemática: "Quais conhecimentos profissionais são mobilizados a partir de atividades de formação ofertadas aos formadores de professores das licenciaturas em Ciências Humanas e Sociais no âmbito da UFFS?" Interessa-nos a formação dos formadores de professores por considerarmos que este processo se constitui em um dos principais mecanismos de qualificação dos percursos de formação inicial de professores que atuam na educação básica. Além disso, a escassez de pesquisas centradas no desenvolvimento profissional de formadores de futuros professores contribuiu para a delimitação dessa temática.

A definição do locus da pesquisa deve-se ao fato que a UFFS é uma universidade pública federal, criada em 2009 mediante um movimento popular envolvendo lideranças regionais e a população dos três estados da Região Sul do Brasil, em sintonia com as demandas de desenvolvimento social, econômico e educacional da mesorregião Grande Fronteira Mercosul. A UFFS tem sede na cidade de Chapecó - SC e possui mais quatro campi, localizados nas cidades de Erechim e Cerro Largo, no Rio Grande do Sul, e nas cidades de Realeza e Laranjeiras do Sul, no Paraná. Tomamos como contexto de pesquisa o campus Chapecó que, por ser unidade sede, oferta maior número de cursos de graduação e, portanto, agrega um número maior de docentes por área do conhecimento. A opção pelas áreas de Ciências Humanas e Sociais deve-se ao fato de haver maior número de licenciaturas no campus Chapecó com foco nestes domínios do conhecimento. Além dos aspectos mencionados, nossa escolha levou em consideração as questões históricas, econômicas e políticas da região onde a UFFS está instalada, na qual impera a cultura oriunda da colonização majoritariamente europeia: da lógica de valorização do trabalho, da produção e do acúmulo de bens, atrelada a uma concepção de educação com função eminentemente propedêutica ao mercado de trabalho (UFFS, 2019).

\section{Conhecimento e Desenvolvimento Profissional de Professores}

Para Roldão (2007; 2014), existe uma relação intrínseca entre a natureza de cada função profissional e o tipo de conhecimento específico necessário para exercê-la, e a docência não é exceção. Para a autora, a questão fundamental que se coloca para o projeto de formação de professores, independentemente se inicial ou continuada, é: "que conhecimento é necessário ao professor para assegurar a complexa função de ensinar, enquanto ato sustentando de promoção da aprendizagem de alguma coisa por alguém?” (Roldão, 2014, p. 96). Nesta direção, ao refletir sobre a relevância da dimensão do conhecimento na prática docente, Roldão esclarece que na sua perspectiva, parte-se

[...] do pressuposto da absoluta centralidade do conhecimento profissional, embora enquadrado na teia de todos os outros elementos, como factor decisivo da distinção profissional, na fase do processo de evolução histórica da profissão que 
se atravessa, claramente marcado pela tensão entre o salto para um nível mais consistente de profissionalidade ou o risco de recuo para situações de proletarização e funcionarização reforçadas. (Roldão, 2007, p. 96, grifo nosso).

Ao assumirmos a centralidade do conhecimento profissional à docência, nos reportamos aos trabalhos de Lee Shulman, psicopedagogo norte-americano, que desde os anos de 1980 tem se dedicado a pesquisar e categorizar os conhecimentos necessários à prática docente e, portanto, subjacentes aos processos formativos. Em suas pesquisas iniciais, Shulman (1986) evidenciou uma tríade de conhecimentos necessários à docência - bem aceita na comunidade acadêmica -, constituída por content knowledge ${ }^{1}$, pedagogical content knowledge ${ }^{2} \mathrm{e}$ curricular knowledge . Posterior a esse trabalho, em 1987, Shulman incorporou outras quatro categorias de conhecimentos a esta categorização: pedagogical content knowledge, knowledge of learners and their caracteristics, o knowledge of educational contexts, knowledge of educational ends, purposes and values, culminado em um modelo constituído de sete categorias (SHULMAN, 1987).

Para Shulman (1986), o content knowledge refere-se ao conhecimento do conteúdo propriamente dito, isto é, o conhecimento científico sobre o objeto que compõe o domínio específico da disciplina de ensino. Ele enfatiza que esta categoria de conhecimento ultrapassa os limites da teoria e do acúmulo das informações, adentrando na questão da organização estrutural destes. Acrescenta, ainda, que este conhecimento possibilita ao professor, além de explicar um fato científico, explicar onde este se insere em uma área de estudo, como se chegou àquelas informações ou porque são relevantes.

O pedagogical content knowledge, na perspectiva de Shulman (1986), define o conhecimento que circunscreve a dimensão didática, ou seja, o repertório de formas, estratégias e representações que o docente possui para explicitar o content knowledge. Este conhecimento profissional requer que o professor tenha clareza dos graus de dificuldade de cada conteúdo, do que torna determinado conteúdo mais fácil ou mais difícil de ser ensinado e assimilado. $\mathrm{O}$ autor diz que esta dimensão do conhecimento profissional precisa ser a mais ampla possível, pois os alunos nunca são os mesmos, não são uniformes e não chegam "vazios" à sala de aula: apresentam distintas bagagens pregressas de conhecimentos, diferentes potencialidades e dificuldades (Shulman, 1986).

O curricular knowledge constitui-se como a base de conhecimento sobre o espectro de programas e materiais didáticos, projetados especificamente para ensinar determinados conteúdos e em diferentes níveis. É a partir do conhecimento curricular que teoria e prática se associam, embasando a prática profissional do professor. De acordo com Shulman (1986), esta categoria de conhecimentos equilibra a tensão recorrente entre conteúdo e didática, em que geralmente o foco do ato de ensinar tende a ficar em um dos dois lados. Essa polarização é evidenciada pelo autor na problematização acerca da tensão entre conteúdo científico e pedagogia desde as universidades medievais até correntes mais modernas de pensamento pedagógico (Shulman, 1986).

Ao explicitar e detalhar os distintos conhecimentos que permeiam a prática docente, Shulman (1986) indica a complexidade e especificidade do ato educativo, apontada por 
Roldão (2007), que é aquilo constitui sua profissionalidade. A concepção destes autores, que enfatiza os conhecimentos necessários à docência como forma de legitimar a profissão e intelectualizar o professor, corrobora a perspectiva de Giroux (1997), que defende a necessidade de rompermos com a concepção de professor como um profissional prático.

É importante ponderar que o ponto de vista de Shulman é o das pedagogias norteamericana e europeia clássica. Entretanto, pesquisas de Tanuri (2000), Vieira e Gomide (2008), Saviani (2009) e Almeida e Richit (2018), entre outros, identificam, na educação brasileira e nos programas nacionais de formação de professores, as tensões apontadas nas pedagogias estrangeiras ao longo dos séculos XIX e XX, isto porque tais pedagogias foram incorporadas nos processos formativos e educativos em nosso país. Parte destas tensões, especialmente àquelas relacionadas à mediação entre conteúdo e pedagogia - teoria e prática -, tomam importante lugar na conceptualização de profissionalidade docente, em que ser professor não é dom, nem vocação: "É ser um profissional de ensino, legitimado por um conhecimento específico exigente e complexo, de que procurámos clarificar algumas dimensões" (Roldão, 2007, p. 102).

Neste sentido, a compreensão dos distintos conhecimentos basilares à docência pode favorecer o equilíbrio entre estes na prática pedagógica e nos processos formativos, evitando o que Roldão (2014) chamou de "movimentos pendulares" e Saviani (2012) chamou de "curvatura da vara": as oscilações extremas e intermitentes de foco na prática educativa e formativa que ora atribuíam demasiada ênfase na teoria, ora relegavam-na a um segundo plano em detrimento de uma prática esvaziada de conteúdo. E tais tensões precisam permear as discussões e reflexões nos processos e percursos formativos.

Sobre isso, Nóvoa (1999) argumenta que não é possível perspectivar mudanças no cenário educacional sem antes pensar a formação de professores. $\mathrm{O}$ autor chama a atenção para o fato de que é preciso entender formação não apenas como "programa de formação": é necessário reformular a concepção de formação situando-a ao longo dos diferentes ciclos de vida e da carreira do professor, numa trajetória de desenvolvimento pessoal e profissional. É necessário integrar as dimensões e conhecimentos do trabalho pedagógico cotidiano da profissão docente, tornando tais dimensões e conhecimentos essenciais à constituição do professor como profissional do ensino (Nóvoa, 1999).

Além disso, Ponte (1994) ressalta o caráter de incompletude da formação inicial docente. Para ele, o professor não se torna um profissional completo ao obter sua habilitação, pois os conhecimentos adquiridos antes e durante a formação inicial precisam ser aprofundados para o efetivo exercício da profissionalidade ao longo da carreira. Afirma, assim, que o desenvolvimento profissional do professor pressupõe o reconhecimento da necessidade de aquisições cognitivas diversas ao longo da carreira. É neste movimento que o profissional se constitui professor de facto (Ponte, 1994).

Em sinergia com as ideias destes dois autores portugueses, as brasileiras Bazzo (2007) e Gatti e Barreto (2009) propõem uma ressignificação do conceito de "formação continuada": uma reconceitualização que desloque esse processo da função exclusiva de preencher lacunas da formação inicial para o espectro de atividades que promovam o crescimento do professor, o fortalecimento da prática e da identidade docente. 
Nesta concepção de formação como um contínuo ao largo da vida profissional, o conceito subjacente é o de desenvolvimento profissional. O processo de formação é definido como um movimento orientado a responder aos diversos desafios que se sucedem no que se poderia identificar como diferentes fases da vida profissional: o início da carreira, o processo de desenvolvimento e os tempos mais avançados em que o professor consolida sua experiência profissional (Gatti, Barreto; 2009, p. 202-203, grifo nosso).

Em outras palavras, a concepção de formação transcende a dicotomia formação inicialcontinuada, pois o espectro de atividades, tanto institucionalizadas e formais como espontâneas a qualquer tempo de carreira, é entendido como processo formativo, dentro do contexto do desenvolvimento profissional docente, caracterizando um processo que ocorre de dentro para fora (Nóvoa, 1999). Nesta perspectiva, Ponte (1994) chama a atenção para a natureza humana e processual da formação docente, cujo foco e intencionalidade priorizam o desenvolvimento pessoal e profissional do professor, que é sujeito do processo de ressignificação do conhecimento e das aprendizagens que realiza ao longo da carreira.

Assim concebido, o desenvolvimento profissional envolve princípios fundamentais, tais como a constituição de conhecimentos basilares à docência, a realização de aprendizagens profissionais ao longo da carreira, a assimilação e modificação da cultura profissional, as mudanças na prática, as condições políticas e contextuais da docência (Richit, Ponte e Tomasi, 2021). Portanto, a concretização de processos formativos na perspectiva do desenvolvimento profissional docente pressupõe um conjunto de esforços sistemáticos para promover mudanças nas práticas em sala de aula, em suas atitudes e crenças e nos resultados de aprendizagem dos alunos (Guskey e Huberman, 1995).

\section{Profissionalidade e Desenvolvimento de Formadores de Futuros Professores}

A literatura relativa à formação de professores evidencia certa dispersão sobre o que se entende por formação de formadores. Algumas vezes, a expressão formação de formadores é usada para designar o processo de formação de futuros professores (graduandos de licenciatura); outras refere-se ao campo de atuação dos profissionais da educação professores ou não - que promovem ou desenvolvem ações de formação continuada. Em nosso estudo, a formação de formadores de professores refere-se ao processo de formação continuada do docente universitário, atuante em cursos de licenciatura, ou seja, o formador de futuros professores. Ressaltamos, porém, que designar este processo formativo como formação continuada é inadequado em face ao conceito de desenvolvimento profissional. Argumentamos, assim, por uma concepção de formação não apenas contínua, mas coerente, dialética e permanente. 
Gatti e Barreto (2009) afirmam que a qualidade das atividades formativas tem relação com a formação dos profissionais que promovem essas ações, os quais precisam dispor de embasamento teórico, conceitual e prático, bem como estarem envolvidos e comprometidos com a sua principal missão, que é formar futuros professores. Esse comprometimento solicita fortes e positivas concepções profissionalidade docente, ou seja, daquilo que diferencia o professor de outros profissionais, bem como um domínio dos conhecimentos que sustentam e legitimam a ação docente. As autoras acrescentam que a formação continuada, em especial, carece de uma identidade sólida acerca de si própria e sobre o ato de ensinar, de quais subsídios teóricos e técnicos necessita. Ressaltam, também, que muitos formadores não dispõem de conhecimentos teóricos ou práticos necessários para preparar os estudantes de licenciatura, os futuros professores que estão formando.

Neste movimento de reflexão sobre formação e desenvolvimento profissional, a formação de formadores ganha relevância no cenário nacional, pois uma sólida formação dos formadores é essencial para o desenvolvimento de novas gerações de professores. Além disso, pesquisas

sobre processos formativos para o desenvolvimento profissional do professor indicam que o tema da formação dos formadores merece atenção. A qualidade da formação inicial e do desenvolvimento profissional dos professores tem relação com a preparação dos profissionais que atuam como formadores neste trabalho, seu domínio conceitual e prático e seu envolvimento e compromisso com a formação de educadores (Gatti, Barreto; 2009, p. 229).

Nesta direção, Vieira e Araújo (2016), ao investigarem o impacto do trabalho de Shulman e sua proposta de categorização dos conhecimentos profissionais de professores na produção nacional, apontam à ênfase na dimensão do conhecimento didático. Nas produções encontradas em levantamento bibliográfico na Associação Nacional de Pós-Graduação e Pesquisa em Educação (ANPED), os trabalhos mais referenciados tratam do teaching knowledge 4 , evidenciando o interesse pela dimensão que tem grande impacto na profissionalidade docente.

Com relação à categorização dos conhecimentos profissionais de professores, as autoras chamam a atenção para o fato de que

[...] parece-nos que as ideias e temas estudados por Shulman não são, de fato, utilizadas como base teórica das pesquisas produzidas no Brasil, pois, embora presente nos trabalhos, em geral, o autor é mencionado de forma superficial, com pouco ou até mesmo sem aprofundamento e reflexão/discussão acerca do conteúdo citado. Neste sentido, reiteramos que o conhecimento pedagógico do conteúdo, considerada categoria distintiva do autor em relação aos demais pesquisadores que tratam da formação e profissionalização docente, não tem sido objeto de análise mais profunda, o que poderia evidenciar certo descaso com o tratamento pedagógico do conteúdo dentro do grande tema dos saberes docentes (Vieira; Araújo, 2016, p. 96, grifo nosso). 
Portanto, o trabalho de Shulman de categorizar, compreender e detalhar as componentes do conhecimento profissional necessário ao professor pode ser chave para o entendimento da própria profissionalidade docente em cursos de licenciatura. Este entendimento pode produzir reflexos positivos nas práticas dos professores, tais como maior articulação entre teoria e prática, revisão dos métodos e posturas avaliativas, maior consciência crítica a respeito do que se ensina e do porquê se ensina, entre outros aspectos.

Assim, a formação dos formadores de professores constitui-se em contexto de aquisição de novos conhecimentos, socialização de novas práticas e discussão da própria formação docente, em face ao qual a universidade assume lugar de destaque. De acordo com Zabalza (2004) e Nóvoa (1999), o espaço universitário é locus privilegiado de formação, e, portanto, os profissionais que aí atuam precisam continuamente desenvolver suas capacidades e conhecimentos, rever e atualizar as práticas pedagógicas.

Nesta direção, Cunha e Zanchet (2014) problematizam a docência na universidade, que se concretiza no contexto das tensões na gestão das relações aí estabelecidas, envolvendo ensino e pesquisa e, por conseguinte, o impacto social delas decorrente. A docência é, portanto, "uma ação complexa, que exige investimento no desenvolvimento profissional dos professores" (Cunha e Zanchet, 2014, p.1).

Entretanto, Gatti e Barreto (2009) advertem que a discussão sobre o locus não deve obscurecer a questão primordial do debate na temática, que é a necessidade de se reformular a concepção de formação do professor. E neste sentido, as perspectivas de conhecimentos profissionais (Shulman, 1986; 1987) e desenvolvimento profissional docente (Cunha e Zanchet, 2014; Gatti e Barreto; 2009; Bazzo, 2007; Zabalza 2004) se complementam na medida em que argumentam pela constituição de uma profissionalidade docente embasada em um conjunto altamente específico de conhecimentos.

No âmbito da formação de professores de nível universitário, mais especificamente os atuantes em licenciaturas (escopo deste trabalho), as concepções de profissionalidade docente assumem centralidade por impactarem de forma imediata no trabalho cotidiano docente e, sobretudo, na concretização da sua finalidade maior: na formação dos futuros professores e na sua prática futura. Essas concepções influenciam, também, o modo pelo qual os conhecimentos subjacentes aos percursos formativos são promovidos nas práticas pedagógicas nos cursos de licenciatura, à medida que oferecem subsídios a uma prática profissional qualificada, reflexiva e ressignificada.

Relativamente à UFFS, cenário da nossa pesquisa, o conhecimento dos contextos, categoria identificada por Shulman (1987), revelou-se importante devido às particularidades da universidade, tais como a posição geográfica afastada de grandes metrópoles e centros culturais, por ser a primeira universidade federal da região, por acolher a um público de estudantes majoritariamente dessa região interiorana e que cursaram integralmente o ensino médio em instituições públicas, entre outras características próprias da instituição e da região (UFFS, 2019). 


\section{Metodologia}

O estudo baseou-se na perspectiva qualitativa de pesquisa (Denzin e Lincoln, 2006) como forma de enfatizar a natureza eminentemente social do processo formativo, examinando-o à luz dos diferentes significados e valores que assume para cada docente participante, como influenciam suas práticas e como desenvolvem conhecimentos relativos à docência. Assim, a pesquisa qualitativa contempla nosso objetivo de constituir dados sobre vivências e experiências de formação dos docentes dos cursos de licenciatura da UFFS e interpretá-los, atribuindo-lhes significados e representando estes significados. O trabalho de interpretação dos dados assumiu um viés mais analítico do que descritivo.

Para a constituição dos dados nos pautamos no conceito de triangulação, que encontra respaldo no trabalho de Denzin e Lincoln (2006), para os quais a multiplicidade de métodos de coleta de dados é inerente à abordagem qualitativa. Esclarecemos, ainda, que a análise também se apoiou no conceito de triangulação, uma vez que dados de diferentes fontes foram cotejados na busca por categorias de análise, na interpretação e discussão destas categorias, bem como na sistematização dos resultados.

O processo de constituição dos dados abrangeu as seguintes etapas: levantamento do ordenamento legal, de órgãos e instituições de âmbito federal e da UFFS, relativos à formação de pessoal docente de nível superior; compilação de documentos provenientes das reuniões de professores e, especialmente, organização, programação e avalição das atividades formativas promovidas na/pela UFFS. Além disso, envolveu a aplicação de questionários não identificados aos professores dos cursos de licenciatura das áreas de Ciências Humanas e Sociais da UFFS, que foi respondido por 17 professores (indicados na análise por letras do alfabeto pelo fato de que os questionários não eram identificados e não haver interesse em associar às respostas a gênero ou outro aspecto de natureza pessoal), bem como condução de entrevistas semiestruturadas com quatro docentes (Artur, Inácio, Simone e Natália - nomes fictícios), dentre aqueles que responderam ao questionário, os quais se disponibilizaram ${ }^{5}$ a nos conceder seus depoimentos em entrevista.

O material empírico da pesquisa constituiu-se dos documentos recuperados na internet, coletados junto à Diretoria de Orientação Pedagógica (DOP) e ao Núcleo de Apoio Pedagógico (NAP) da UFFS campus Chapecó e materiais constituídos durante a pesquisa (questionários e transcrições de entrevistas). Estes materiais foram organizados em grupos, conforme quadro a seguir. 
Quadro 1: Conjuntos de materiais empíricos

\begin{tabular}{|c|c|c|}
\hline Grupo & Descrição & Documentos constituintes \\
\hline 1 & Políticas de formação de formadores & $\begin{array}{l}\text { a) Legislações, diretrizes, } \\
\text { normativas e resoluções de nível federal } \\
\text { (CAPES, CNPq e MEC). } \\
\text { b) Diretrizes, normativas e } \\
\text { resoluções de nível regional (UFFS). }\end{array}$ \\
\hline 2 & Perfil do docente formador da UFFS & $\begin{array}{l}\text { a) Respostas à pesquisa de } \\
\text { opinião docente aplicada pela DOP. } \\
\text { b) Relatório consolidado do } \\
\text { questionário aplicado aos docentes das } \\
\text { licenciaturas da UFFS. }\end{array}$ \\
\hline 3 & Demandas de formação docente da UFFS & $\begin{array}{l}\text { a) Atas de reuniões da DOP e } \\
\text { NAP Sistematizações de } \\
\text { b) } \\
\text { memorandos, de } e \text {-mails e de documentos } \\
\text { dos colegiados relativos às demandas } \\
\text { temáticas de formação docente. } \\
\text { c) Devolutivas do questionário } \\
\text { aplicado aos docentes das licenciaturas da } \\
\text { UFFS. }\end{array}$ \\
\hline 4 & Registros de formação docente da UFFS & $\begin{array}{l}\text { a) Relatórios, dossiês e } \\
\text { calendários de atividades de formação } \\
\text { efetivamente realizadas. } \\
\text { b) DVD's com gravações em } \\
\text { vídeo de atividades de formação. }\end{array}$ \\
\hline 5 & $\begin{array}{l}\text { Sobre a formação docente ofertada pela } \\
\text { UFFS }\end{array}$ & $\begin{array}{l}\text { a) Fichas de avaliação das } \\
\text { atividades de formação da UFFS } \\
\text { preenchidas pelos docentes participantes. } \\
\text { b) Devolutivas do questionário } \\
\text { aplicado aos docentes das licenciaturas da } \\
\text { UFFS. } \\
\text { c) Transcrições das entrevistas } \\
\text { realizadas com docentes das licenciaturas } \\
\text { da UFFS. }\end{array}$ \\
\hline
\end{tabular}

Fonte: Elaborado pelo autor (2019).

Após a organização deste material, procedemos a pré-análise, de acordo com os pressupostos da análise de conteúdo de Bardin (2011), para a qual a pré-análise visa preparar o material para catalogação e seleção, permitindo a formulação de hipóteses e objetivos. A partir da leitura flutuante do material textual, o agrupamos de acordo com o conteúdo e objetivo geral, visando oferecer elementos iniciais para identificar aspectos relacionados aos conhecimentos profissionais promovidos nas ações de formação de formadores de futuros professores da UFFS. 
A análise das políticas de âmbito federal baseou-se em documentos extraídos de três sites: Ministério da Educação (MEC), Coordenação de Aperfeiçoamento de Pessoal de Nível Superior (CAPES) e Conselho Nacional de Desenvolvimento Científico e Tecnológico (CNPq). As ações e políticas de âmbito local (institucional) foram coletadas junto ao site da UFFS. Esclarecemos, entretanto, que não é nosso objetivo tecermos considerações que adentrem o campo das pesquisas referentes às políticas educacionais, mas, sim, analisar a legislação que regula a temática da formação de modo a compreendermos como estes federalismos impactam as políticas e ofertas locais de formação docente em nível superior.

Por fim, a análise do material empírico evidenciou diferentes aspectos relacionados às categorias de conhecimento apresentadas por Shulman, das quais nos dedicamos a abordar o pedagogical content knowledge, que será referido como conhecimento didático no escopo deste trabalho.

\section{Aspectos do Conhecimento Didático Evidenciados no Desenvolvimento Profissional de Formadores de Futuros Professores}

A perspectiva do pedagogical content knowledge 6 de Shulman (1987) nos remete ao que Roldão (2014) denomina didática, ou seja, o conhecimento específico docente que circunscreve as estratégias de ensino do saber científico e de gestão do próprio processo educativo. Esta categoria, que denominamos conhecimento didático, constituiu-se a partir da convergência entre diferentes aspectos evidenciados no material empírico, sistematizados em três eixos principais: abordagens de ensino, processos de avaliação e compreensão sobre as dificuldades dos alunos.

Relativamente à subcategoria abordagens de ensino, a análise sobre os documentos oficiais evidencia que a Lei de Diretrizes e Bases da Educação Nacional (LDB) é omissa a respeito da formação para a docência na educação superior. Os art. 65 e 66 da LDB, cuja redação permanece inalterada desde a original, evidenciam este aspecto:

Art. 65. A formação docente, exceto para a educação superior, incluirá prática de ensino de, no mínimo, trezentas horas.

Art. 66. A preparação para o exercício do magistério superior far-se-á em nível de pós-graduação, prioritariamente em programas de mestrado e doutorado. (BRASIL, 1996).

A LDB, primeiramente, exime que a formação docente para o ensino superior contemple a prática de ensino, comumente denominada "estágio" e, na sequência, preconiza a preparação para a docência superior, prioritariamente, em cursos de pós-graduação stricto sensu. Entretanto, quanto à oferta de disciplinas como "Didática do Ensino Superior" ou "Metodologia do Ensino Superior" e análogas, que tratam do método de ensino para a educação superior, inexistem garantias ou orientações legais que as integrem aos currículos dos programas de pós-graduação. 
Além disso, os estágios de docência, obrigatórios apenas para pós-graduandos bolsistas, não são garantia de aprendizagem da didática necessária, conforme apontam Pereira e Medeiros (2011), os quais ressaltam que estes momentos formativos são muito mais de caráter observacional do que participativo, assim como há pouco tempo e espaço para discussões aprofundadas sobre teorias, metodologias e estratégias pedagógicas.

E mais, a busca pelos programas da CAPES com este foco revelou que está em curso um processo de desvalorização da formação para a docência, visto que importantes programas foram extintos e outros estão em vias de extinção. Por exemplo, as iniciativas de cursos interinstitucionais de pós-graduação, a exemplo do MINTER e DINTER, vêm sendo sistematicamente descontinuadas, de modo que a concessão de bolsas e auxílios tem se tornado o principal dispositivo para a formação de pessoal para o nível superior. Além disso, a descontinuidade do programa PRODOCÊNCIA é outro grande retrocesso, visto que era o único programa com foco nas licenciaturas e cujos objetivos inclúam a "valorização da carreira docente".

Esses aspectos foram evidenciados também no material empírico proveniente dos questionários, entrevistas e documentos da DOP-UFFS. A análise das respostas individuais fornecidas ao questionário permitiu-nos estimar o quantitativo de docentes que obtiveram sua maior titulação durante a atuação na UFFS, assim como as temáticas abordadas nos trabalhos de conclusão desses processos formativos (tema das dissertações e teses defendidas). Embora esses percursos formativos tenham sido realizados externamente à UFFS, nos permitem desenhar um mapa a respeito do interesse dos docentes por objetos de investigação relacionados à profissionalidade docente na universidade. Este aspecto evidencia, por um lado, a necessidade de o docente da educação superior desenvolver conhecimento relativo à docência e, por outro, que a dimensão do conhecimento didático é uma fragilidade da formação do professor universitário.

Em resposta à pergunta número 7 do questionário, que indagava sobre a temática pesquisada pelos docentes em suas pós-graduações, um participante, que obteve seu doutoramento entre os 05 (cinco) e 10 (anos) da criação da UFFS e atua na instituição neste período, indicou a temática “Trabalho docente no Ensino Superior" (Docente Q, 27/03/2019) como tema de pesquisa de sua maior titulação (tese de doutorado). Essa resposta corrobora à subcategoria relativa ao conhecimento didático, denominada abordagens de ensino, que em nosso estudo abarca as abordagens e estratégias de ensino dos conteúdos dos componentes curriculares, organização, gestão e escolhas pedagógicas.

Ao inquirirmos os professores sobre as percepções acerca das ações ofertadas pela UFFS, em resposta à pergunta número 20 do questionário, "Dentre as ações que você participou, qual(is) a(s) temática(s) que considerou mais relevante(s)?", um docente indicou a temática "Discussões sobre a docência universitária" (Docente K, 18/03/2019) como prioridade de formação e, portanto, como ação mobilizadora de aspectos relativos ao conhecimento didático, especificamente as abordagens de ensino.

Ao analisar a cronologia das ações de formação promovidas pela UFFS de 2010 a 2015, identificamos várias atividades centradas nas abordagens de ensino. Dentre elas destacam-se 
as ações com foco no uso de tecnologias digitais na prática pedagógica e em abordagens diferenciadas para alunos com necessidades educacionais especiais:

Treinamento para o uso de telas interativas (15/04/2011)

Capacitação: "Moodle" (11/08/2011)

Inclusão de alunos com necessidades educacionais especiais no Ensino Superior:

vivencias, desafios e perspectivas (19/09/2011)

Treinamento pedagógico para o uso da tela interativa $(21 / 11 / 2011)$

O trabalho pedagógico com alunos surdos e cegos (28/11/2011)

Capacitação: "Telas interativas" (23/02/2012)

Capacitação: "Uso do Moodle" (24/02/2012)

Palestra "O trabalho pedagógico com alunos surdos" (07/03/2012)

Palestra "O trabalho pedagógico com alunos cegos" (12/03/2012)

Palestra "A pesquisa como estratégia de ensino" (23/05/2012)

Palestra "Estratégias de ensino e avaliação para as Ciências Exatas na Educação Superior" (24/09/2012)

Formação docente: trocas de experiências didático-pedagógicas em turmas com estudantes haitianos $(22 / 11 / 2015)$.

Artur, um dos professores entrevistados, evidencia este aspecto ao comentar sobre uma mudança de paradigma após sua participação, no âmbito da UFFS, no colegiado do curso de Ciências Sociais, uma vez que ele era oriundo do bacharelado tanto por formação inicial como por experiência imediatamente anterior à docência na UFFS. Ele indica, neste movimento, a mobilização de conhecimento relativo às abordagens de ensino e à adaptação metodológica destas abordagens para sua nova realidade de sala de aula, que agora o colocava no papel de formador de futuros professores.

Nós temos a obrigação de formar professores, em compensação, nós não temos uma formação para isso, não somos licenciados, né? Então nós tínhamos que ver o que nós poderíamos oferecer dentro daquela nossa bagagem. (Transcrição da entrevista de Artur, concedida em 02/05/2019).

Inácio enfatiza este aspecto do conhecimento didático ao explicitar sua visão sobre o desenvolvimento da prática profissional enquanto formador de futuros professores para a educação básica. Ao ser questionado sobre sua percepção acerca do impacto das formações da UFFS em sua docência como formador, Inácio afirma:

E ai a gente ajuda os alunos a construírem um conjunto de conhecimentos naquela área do conhecimento, depois os habilita para trabalharem na educação a partir daquele conjunto de conhecimentos que eles sistematizaram enquanto eles estavam na universidade. [Isto mostra] o impacto que essas formações trouxeram e as mudanças que operaram na forma como a gente atua em sala de aula. [...]. Algumas foram oficinas, outras foram palestras, algumas foram mais focadas, outras mais amplas. Eu acredito que elas têm sido fundamentais, super 
importantes, para eu repensar a minha atuação dentro da sala, dentro da universidade. (Transcrição da entrevista de Inácio, concedida em 16/04/2019).

Corroborando ao professor Inácio, Simone ressalta a influência das atividades formativas promovidas pela Universidade na mobilização de conhecimentos referentes às abordagens de ensino, indicando vivências marcantes.

William: Essas formações tiveram impacto ou influência na organização e gestão do trabalho docente, na instrumentalização do trabalho, nas atividades que antecedem e sucedem a sala de aula?

Simone: Sim, seguramente. Claro, quando você pensa, planeja, organiza sua aula... Esse movimento está passando por você. Aconteceu uma aula, aconteceu um processo... É formação continuada. E a universidade oferece isso. E ela poderia ser ainda melhor [...]. (Transcrição da entrevista de Simone, concedida em 17/04/2019).

William: Então você diria que o Fórum das Licenciaturas foi a atividade formativa para professores formadores de professores mais impactante que a UFFS ofereceu?

Simone: Sim, a mais impactante. Porque ela, de fato, mexeu com a nossa ação. Com aquilo que nós vínhamos fazendo [...]. (Transcrição da entrevista de Simone, concedida em 17/04/2019).

Adicionalmente, Inácio relata uma vivência que considera ter mobilizado conhecimentos sobre abordagens e estratégias de ensino, atividade que, vale destacar, foi iniciativa sua e de seus colegas de colegiado de Curso:

E eu fiquei responsável ali pelo GT que discutiria a relação entre disciplinaridade e interdisciplinaridade na formação de professores. Eu até organizei, com apoio dos colegas e muito com apoio do curso de Geografia, um debate sobre isso no ano passado [...]. (Transcrição da entrevista de Inácio, concedida em 16/04/2019).

Ao ser questionada sobre a influência das atividades promovidas pela UFFS na dimensão da pesquisa, Simone indica que esta perspectiva se faz presente nas ações da Instituição, o que oportunizou aos docentes mobilizar conhecimentos relativos às estratégias de ensino, que se espraiaram para questões curriculares e de articulação da tríade universitária (ensino, pesquisa e extensão).

Sim, nós tivemos formações nesse sentido e, sim, influenciaram bastante. Inclusive no sentido de a gente compreender melhor e a gente poder repensar o ensino como pesquisa, e poder pensar a pesquisa não só no sentido da pesquisa estruturada nos grupos de pesquisa, mas também pensar a pesquisa como estratégia de ensino, como estratégia pedagógica de ensino. [...]. De pensar o processo de ensino de um componente curricular, por exemplo, tendo a pesquisa como ferramenta. Construindo com os estudantes, por exemplo, um conjunto de 
problemáticas, de problematização, e transformando essas problematizações em objetos de aprofundamento. Quer dizer, construindo ali na organização pedagógica do componente, usando elementos de pesquisa para isso, eu acho isso uma coisa bem importante. (Transcrição da entrevista de Simone, concedida em 17/04/2019).

A professora Natália, entretanto, ao ser questionada sobre a oferta de atividades centradas no desenvolvimento de conhecimento didático, sinaliza uma carência de atividades formativas nesse sentido, conforme sinaliza seu relato:

Não, não há essa preocupação, me parece. [...]. Por exemplo, não há uma preocupação de trabalharmos diferentes metodologias, olhando para a questão mais didática, ou metodológica [...]. Nós temos uma carência muito grande de oferta, por exemplo, sobre como a gente poderia trabalhar Geografia em uma perspectiva que não seja a do livro didático. Matemática idem. História idem. (Transcrição da entrevista de Natália, concedida em 09/04/2019).

A questão 22, que finalizava o questionário aplicado aos docentes, inquiria: "Em que medida as ações de formação que frequentou na UFFS contribuíram para o seu desenvolvimento e prática profissionais?" Três respondentes selecionaram a alternativa "Levaram-me a promover mudanças em minha prática de sala de aula", indicando a mobilização de conhecimentos sobre abordagens de ensino a partir das ações institucionais.

Contudo, ao analisarmos as devolutivas à pergunta número 21 do questionário, "Quais temáticas relevantes de seu ponto-de-vista foram pouco desenvolvidas nas atividades que frequentou?", identificamos elementos que reforçam a percepção da docente Natália, sinalizando a insuficiência de ações comprometidas com a mobilização de conhecimentos acerca das metodologias e estratégias de ensino.

$\mathrm{Na}$ sistematização das temáticas sugeridas nas demandas formativas coletadas pela Diretoria de Organização Pedagógica (DOP) e pelo Núcleo de Apoio Pedagógico (NAP), as abordagens de ensino são mencionadas com frequência. Essa demanda evidencia que embora este aspecto vem sendo contemplado nas atividades formativas, há demanda para mais ações sobre conhecimento didático, talvez pela complexidade e abrangência inerente à temática. Esta carência foi evidenciada também nas devolutivas ao questionário, que apontam essa temática como a mais relevante no espectro das ações promovidas pela UFFS, mas, ao mesmo tempo, ressalvam que precisa ser melhor desenvolvida.

Dimensão didática (Docente F, 02/12/2018)

Acredito que deveria haver mais discussões quanto à docência universitária, questões didático-pedagógicas (Docente K, 18/03/2019)

Didática geral e propostas de aulas (Docente L, 19/03/2019)

[...] novas tecnologias educacionais; metodologia do ensino superior (Docente O, 23/03/2019).

(Respostas ao questionário) 
Didática do Ensino Superior

Didática do Ensino Superior

(Demandas de formação do colegiado de Geografia, 2012 e 2014)

Didática: pensamento crítico

Metodologia da Ensino Superior

Oficinas

(Demandas de formação do colegiado de Ciências Sociais, 2014)

Docência no Ensino Superior

(Demandas de formação do colegiado de História, 2014)

Em ficha de avaliação da atividade de formação "Palestra 'Currículo'”, realizada em 23/03/2012 no campus Chapecó, em resposta à questão número 6 ("Que reflexões você destacaria do evento?") um docente indagou: "Como lidar com tantos alunos diferentes na sala de aula? Como ensinar crianças com dificuldades de aprender?", apontando a necessidade de desenvolver conhecimento relacionado ao ensino para casos específicos, evidenciada aqui pelo uso da palavra "como"; e uma possível conexão com as licenciaturas e a formação à educação básica, ao preocupar-se com o ensino de "crianças".

Portanto, relativamente à subcategoria 'abordagens de ensino', a análise evidencia a prevalência desta dimensão nas ações promovidas pela UFFS, conforme indicado pelo quantitativo de atividades ofertadas e pelos percursos formativos dos docentes entrevistados. Há, todavia, demanda por mais atividades sobre a temática, conforme revelado pelos questionários e na sistematização das demandas de formação encaminhadas pelos colegiados das licenciaturas da Instituição.

A análise evidenciou, também, aspectos relativos ao processo de avaliação no âmbito da docência nos cursos de licenciatura na referida Instituição, que evidenciam a preocupação com a natureza e a finalidade assumida por este processo, bem como sobre a especificidade da avaliação em áreas distintas. A sistematização das atividades de formação promovidas pela UFFS no período de 2011 a 2017 evidencia temas associados às formas de avaliação na educação superior:

Conferência "Avaliação no Ensino Superior" (21/06/2011)

Minicurso "Avaliação: propostas para o sistema de avaliação discente da UFFS” (31/08/2011)

Palestra "Avaliação no Ensino Superior" (08/03/2012)

Palestra "Estratégias de ensino e avaliação para as Ciências Exatas na Educação Superior" (24/09/2012).

Para Artur, essa subcategoria do conhecimento didático é destacada como aspecto basilar no contexto das mudanças metodológicas efetivadas em sua prática ao transitar de professor de futuros bacharéis para formador de futuros professores: 
E você sabe, por aquela conversa inicial com os estudantes, que você vai ter que calibrar, digamos, um nivel de exigência, quanto às atividades, não quanto à formação, mas quanto às atividades para aquele público [...]. (Transcrição da entrevista de Artur, concedida em 02/05/2019).

A professora Simone, ao ser questionada se percebe influência das atividades formativos da UFFS em sua maneira de conceber a avaliação, afirma que este conhecimento e reconhecimento ocorreu, e não somente por meio de atividades formais ou institucionalizadas de formação:

Essa questão do processo de avaliação é uma questão que, na minha caminhada, eu sempre vou mexendo. Um pouco por conta dos processos de formação, um pouco por conta dos estudos na área, do aprofundamento nas teorias educacionais... É sempre um elemento que eu vou mexendo. Procurando sempre melhorar. Seguramente, no aspecto da avaliação, foram se transformando bastante coisas para mim. (Transcrição da entrevista de Simone, concedida em 17/04/2019).

Em resposta à questão final do questionário, que indagava sobre as contribuições das ações promovidas pela UFFS para o desenvolvimento profissional dos professores, quatro respondentes marcaram a opção "Levaram-me a modificar os processos de avaliação que realizo com os discentes", indicando o impacto das ações na revisão do processo de avaliação, sobretudo na medida em que sugerem uma perspectiva que concebe o processo avaliativo como diagnóstico da aprendizagem dos alunos.

Esta subcategoria foi ressaltada também no âmbito das fragilidades formativas apontadas pelos docentes, conforme evidenciado pelo material empírico. A "avaliação [do processo] ensino-aprendizagem" foi a resposta para a questão 21 do questionário ("Quais temáticas relevantes de seu ponto-de-vista foram pouco desenvolvidas nas atividades que frequentou?") fornecida pelo Docente O (23/03/2019). Não apenas esta resposta, mas também a sistematização das demandas por formação docente no ano 2014 evidencia a necessidade de maior desenvolvimento de um conhecimento relativo aos processos de avaliação realizados na instituição:

Avaliação docente e discente

Metodologia da autoavaliação

(Demandas de formação docente do colegiado de Ciências Sociais, 2014)

[...] o que cobrar na hora da avaliação, como cobrar, tarefas e leituras de casa

(Demandas de formação docente do colegiado de Filosofia, 2014).

Esta subcategoria do conhecimento didático, embora menos frequente, coloca-se como uma prioridade em termos dos temas contemplados nas ações formativas, conforme evidenciado nos depoimentos dos entrevistados, apontando para a necessidade de se repensar os processos de avaliação na docência universitária. 
A terceira subcategoria do conhecimento didático abordada diz respeito ao diagnóstico das dificuldades dos alunos e às estratégias que mobilizadas para dirimi-las. Artur explicita esse aspecto em dois momentos de seu depoimento. Primeiramente aponta para uma mudança de percepção deflagrada pelo deslocamento de sua prática pedagógica da formação de bacharéis para a formação de professores. A este respeito menciona as dificuldades e medos dos alunos relacionados a componentes curriculares específicos, como o Trabalho de Conclusão de Curso (TCC) e Estágio Supervisionado. Em seguida ele destaca a mudança nas ideias pré-concebidas sobre as percepções discentes acerca destas dimensões (ensino, pesquisa e formação docente) na sua formação enquanto futuros professores. Artur afirma que houve a mobilização de um conhecimento didático específico a respeito da identificação das dificuldades dos acadêmicos. Considera que além dele, possivelmente seus pares, colegas de colegiado, (denotado pelo uso da expressão "a gente”), também realizaram este movimento de mudança de concepção e prática.

Em outro momento da sua narrativa, Artur menciona o período em que assumiu a coordenação do curso de Ciências Sociais, ressaltando a importância deste momento para seu crescimento pessoal e profissional. Ele avalia que essa atividade mobilizou múltiplas percepções sobre seu papel como formador de futuros professores, assim como conhecimentos relacionados ao diagnóstico e gestão das dificuldades dos alunos.

[...] eu me surpreendi, em especial no curso de licenciatura [...] que os alunos tinham mais receio de chegar nos estágios do que necessariamente no TCC, pelo que eu percebia. [...] Eles tinham medo mesmo de estágio. [...] Eu pensava que as pessoas [na licenciatura] estavam mais pré-dispostas a enfrentar esse desafio. Lógico, depois a gente também foi identificando porque eles se sentiam assim [...]. (Transcrição da entrevista de Artur, concedida em 02/05/2019).

Apesar do reconhecimento deste aspecto, Artur não aponta estratégias eventualmente desenhadas para amenizar as carências dos acadêmicos. Além disso, não há alusão a este aspecto do conhecimento didático em outros depoimentos, nas respostas a questionários ou outro material empírico, evidenciando que esta não é uma subcategoria de conhecimento didático que os docentes têm envidado esforços.

Por fim, a análise sinaliza que os professores reconhecem as dificuldades dos alunos, especialmente nas disciplinas específicas e de natureza profissional, tais como os estágios, e de pesquisa, a exemplo do trabalho de conclusão do curso, mas não são mencionadas ações propositivas para minimizá-las. A ausência de tais ações propositivas e o reconhecimento dessa lacuna por parte dos docentes, segundo nossa análise, indica que este aspecto do conhecimento didático para a docência na educação superior precisa ser priorizado. Sinaliza, também, especialmente a partir da entrevista de Artur, que as atividades de gestão - como a coordenação um curso de licenciatura -, contribuem para o desenvolvimento de conhecimentos profissionais de naturezas distintas, tais como o conhecimento do currículo, dos fins e finalidades da licenciatura, do contexto institucional e dos alunos, os quais complementam a dimensão do conhecimento didático. 


\section{Discussão e Considerações Finais}

No que diz respeito ao conhecimento pedagógico do conteúdo (Shulman, 1987), aqui nominado conhecimento didático, a análise evidencia a promoção dessa dimensão nas atividades da UFFS para formadores de futuros professores, com destaque especial à Conferência das Licenciaturas (evento institucional). A indicação deste evento (Conferência) como dispositivo para o desenvolvimento de distintos aspectos do conhecimento didático, especialmente sobre abordagens de ensino e processos de avaliação discente (Roldão, 2007; Shulman, 1986), aparece com certa proeminência no material empírico. A Conferência foi enfatizada como a atividade de maior importância para os professores, tanto pela relevância dos temas abordados quanto pela duração, constituindo uma ação verdadeiramente continuada por estender-se por dois anos e promover profundas discussões sobre a formação de futuros professores em sinergia com as demandas da região.

A Conferência constituiu-se em dispositivo de desenvolvimento profissional docente (Roldão, 2014; Gatti e Barreto, 2009; Nóvoa 1999; Ponte 1994), um processo contínuo e permanente de desenvolvimento profissional de formadores, processo esse que não pode ser aligeirado (Gatti e Barreto, 2009; Bazzo, 2007; Cunha 2005). Além disso, a Conferência oportunizou aos formadores um contexto de discussão, reflexão e crescimento pessoal e profissional (Nóvoa, 1999), no qual assumiram o papel de sujeitos do próprio desenvolvimento profissional (Ponte, 1994; Zabalza, 2004).

$\mathrm{Na}$ dimensão dos conhecimentos didáticos, a perspectiva relacionada às abordagens de ensino para atender acadêmicos com necessidades especiais constituiu-se em temática valorizada para formadores de futuros professores (Bazon et al., 2018), manifestada pela preocupação, em nível da Instituição, com o ensino ofertado e com as necessidades de aprendizagem e desenvolvimento desses alunos. Esta ênfase foi evidenciada em face ao quantitativo de ações sobre esta temática, pelo reconhecimento da importância desse aspecto pelos participantes e pelas contribuições das atividades promovidas pela UFFS para a prática desses professores (Roldão, 2007; 2014).

Destacamos, ainda, o direcionamento das ações formativas para aspectos instrumentais, metodológicos do trabalho docente (Melo, 2010), a exemplo das ações voltadas à instrumentação para uso de telas interativas em sala de aula, sistemas de apoio e gestão do ensino, como o Moodle, e o sistema de videoconferência da Instituição. Oficinas sobre esses recursos foram promovidas continuamente por um período de tempo em virtude da necessidade de preparar os professores que já atuavam e, também, os docentes que chegavam à instituição mediante novas nomeações. Além disso, àquela altura, verificaram-se esforços federais para implementar infraestrutura tecnológica nas universidades públicas, sobretudo aquelas criadas recentemente, como a UFFS. Por consequência, essa prevalência foi alavancada pelas demandas manifestadas pelos docentes, que destacavam a importância destes recursos para a prática pedagógica. 
Acerca dos processos de avaliação, a análise aponta à necessidade urgente de ações e reflexões sobre este aspecto no âmbito das atividades formativas promovidas pela Instituição para os docentes dos cursos de nível superior. A análise do material empírico proveniente dos questionários e das entrevistas, por sua vez, sinaliza a preocupação dos professores em modificar a concepção e os mecanismos de avaliação. Os entrevistados sinalizam que a adaptação dos processos de avaliação ocorre muito em função do perfil dos alunos e das turmas, mediante o conhecimento das suas dificuldades (Shulman, 1987). Concluem que o conhecimento dos alunos e dos contextos (Shulman, 1987) influencia a escolha de metodologias de ensino e de avaliação, a seleção de materiais de ensino, as posturas profissionais e, portanto, a formação dos futuros professores.

Relativamente à identificação e modos de diagnosticar e de trabalhar as dificuldades dos alunos, não identificamos atividades formativas com este foco ou menções propositivas no material empírico. Porém, os docentes entrevistados manifestaram a importância do desenvolvimento deste conhecimento. $\mathrm{E}$ as ações formativas focadas nos estudantes e nas suas demandas centraram-se, sobretudo, no reconhecimento das características dos alunos, dos contextos dos alunos (Shulman, 1987), não contemplando a proposição de estratégias para dirimir essas dificuldades, a exemplo daquelas enfrentadas em determinados componentes curriculares, as quais poderiam ser analisadas e refletidas em relação ao impacto na trajetória dos estudantes e como possível causa de evasão. Ou seja, a evasão, explicitada como uma preocupação institucional e compartilhada pelo coletivo docente, não foi contemplada nas ações formativas da UFFS.

Embora destacado como ponto positivo e relevante das ações promovidas pela instituição, o conhecimento didático é apontado como uma dimensão que precisa ser desenvolvida. Esse indicativo evidencia a importância desta dimensão para a mudança de paradigmas e práticas, favorecendo o desenvolvimento profissional dos formadores de futuros professores (Cunha, 2005), pois não é possível perspectivar mudanças educacionais sem previamente modificar a formação docente (Nóvoa, 1999).

Por fim, ressaltamos a dificuldade em produzir uma categorização cartesiana dos aspectos evidenciados no material empírico. Especialmente nos depoimentos dos formadores, as reflexões desafiaram uma categorização plana, fechada em si mesma. As narrativas dos participantes articulavam de forma coerente e natural uma multiplicidade de conhecimentos, que se fossem analisados isoladamente perderiam seu sentido no âmbito da práxis educativa. Este aspecto ressalta que a profissionalidade docente, especialmente do formador de futuros professores, revela-se rizomática no que diz respeito aos conhecimentos que a embasam.

Além disso, a compreensão sobre o desenvolvimento profissional do formador de futuros professores, mediante o aprofundamento de diferentes aspectos do conhecimento profissional como forma de legitimação da profissionalidade (Roldão, 2007; Gatti e Barreto, 2009; Cunha e Zanchet, 2014), é possível quando reconhecemos as responsabilidades pessoais, profissionais, institucionais, sociais, políticas e éticas imbricadas no processo educativo. É necessário o esforço conjunto de professores, formadores, pesquisadores e instituições para explicitar e concretizar a difícil missão de formar futuros professores, que pressupõe a 
reformulação da concepção de profissionalidade docente na universidade (Cunha, 2005) e na licenciatura. É preciso identificar os contextos e as diferentes demandas de conhecimentos profissionais, propondo ações na perspectiva do desenvolvimento profissional para aqueles que assumem a complexa e desafiadora missão de formar as novas gerações de professores.

\section{Agradecimentos}

Nosso agradecimento especial aos professores e servidores técnico-administrativos da UFFS, que contribuíram para a realização deste estudo. Agradecemos também ao CNPq pelo financiamento (Processo: 305476/2020-3).

\section{Notas:}

1. Conhecimento do conteúdo (tradução nossa).

2. Conhecimento pedagógico do conteúdo (tradução nossa).

3. Conhecimento curricular (tradução nossa). Os demais são: Conhecimento pedagógico geral; Conhecimento dos alunos e suas características; Conhecimento dos contextos educacionais; Conhecimento das finalidades, propósitos e valores da educação. (tradução nossa).

4. Conhecimento docente (tradução nossa).

5. Mediante a indicação, em um campo específico do questionário, de um endereço de e-mail para agendamento da entrevista.

6. Conhecimento pedagógico do conteúdo (tradução nossa).

\section{Referências}

ALMEIDA, W.X.; RICHIT, A. Alternâncias nos processos e políticas de formação de professores no Brasil. Com a Palavra, o Professor. Vitória da Conquista, v. 3, n. 1, jan./abr. 2018, p. 60-80.

BARDIN, L. Análise de conteúdo. São Paulo: Edições 70, 2011.

BAZON, F.V.M. Formação de formadores e suas significações para a educação inclusiva. Educação e Pesquisa. São Paulo, v. 44, e176672, 2018.

BAZZO, V. Constituição da profissionalidade docente na educação superior: desafios e possibilidades. 2007. 265 f. Tese (Doutorado em Educação), Universidade federal do Rio Grande do Sul, 2007.

BRASIL. Coordenação de Aperfeiçoamento de Pessoal de Nível Superior. Bolsas/Estudantes. Brasília, 2018.

BRASIL. Lei no 9.394, de 20 de dezembro de 1996. Brasília, 1996.

CUNHA, M. I. (Org.). Pedagogia universitária: energias emancipatórias em tempos neoliberais. Araraquara: JM Editores, 2005.

CUNHA, M. I.; ZANCHET, B. M. B. A. Desenvolvimento profissional docente e saberes da educação superior: movimentos e tensões no espaço acadêmico. Revista Brasileira de Pesquisa sobre Formação de Professores, v. 6, n. 11, p. 11-22, 2014.

DENZIN, N.K.; LINCOLN, Y.S. (Org.). O planejamento da pesquisa qualitativa: teorias e abordagens. Porto Alegre: Artmed, 2006. 
GATTI, B.A; BARRETO, E.S.S. (Coord.) Professores do Brasil: impasses e desafios. Brasília: UNESCO, 2009.

GIROUX, H. Os professores como intelectuais. Porto Alegre: Artmed, 1997.

GOOGLE. Google Docs. 2018a. Disponível em: <https://www.google.com/docs/about/>. Acesso em: 26 maio 2018.

GUSKEY, T.; HUBERMAN, M. Professional development in education: New paradigms and practices. New York, NY: Teacher College Press, 1995.

MELO, J.R. A formação do formador de professores de matemática no contexto das mudanças curriculares. 2010. 303f. Tese (Doutorado em Educação). Universidade Estadual de Campinas, Campinas, 2010.

MOREIRA, C.S. Formação de formadores de leitura literária: os saberes que articulam suas práticas formativas. 2017. 112f. Dissertação (Mestrado Profissional em Educação: Formação de Formadores). Pontifícia Universidade Católica de São Paulo, 2017.

NÓVOA, A. Os professores na virada do milênio: do excesso dos discursos à pobreza das práticas. Educação e Pesquisa. São Paulo, v. 25, n. 1, jan./jun. 1999, p.11-20.

PEREIRA, É.F.; MEDEIROS, C.C.C. Metodologia do ensino superior nos programas de pós-graduação Stricto Sensu em Educação Física no Brasil: a formação docente em questão. Movimento. Porto Alegre, v. 17, n. 4, out./dez. 2011, p. 165-183.

PONTE, J.P. O Desenvolvimento Profissional do Professor de Matemática. Educação \& Matemática. Lisboa, n. 31, jul./set. 1994, p. 9-20.

RICHIT, A. Estudos de aula na perspectiva de professores formadores. Revista Brasileira de Educação. Rio de Janeiro, v.25, n.2, p.1-24, 2020.

RICHIT, A.; PONTE, J.P.; TOMASI. A.P. Aspects of Professional Collaboration in a Lesson Study. International Electronic Journal of Mathematics Education, v.16, n.1, p.1-14, 2021.

ROLDÃO, M.C. Currículo, didáticas e formação de professores - a triangulação esquecida. In: OLIVEIRA, M.R. (Org.). Professor: formação, saberes e problemas. Porto: Porto Editora, 2014, p. 91-104.

ROLDÃO, M.C. Formação docente: natureza e construção o conhecimento profissional. Revista Brasileira de Educação. São Paulo, v. 12, n. 34, jan./abr. 2007, p. 94-103.

SAVIANI, D. Escola e Democracia. 42 ed. rev. Campinas: Autores Associados, 2012.

SAVIANI, D. Formação de professores: aspectos históricos e teóricos do problema no contexto brasileiro. Revista Brasileira de Educação. Rio de Janeiro, v. 14, n. 40, p. 143-155, 2009.

SHULMAN, L.S. Knowledge and Teaching: Foundations of the New Reform. Harvard Educational Review. Cambridge, v. 57, n. 1, fev. 1987, p. 1-23.

SHULMAN, L.S. Those Who Understand: Knowledge Growth in Teaching. Educational Researcher. Washington, v. 15, n. 2, fev. 1986, p. 4-14.

TANURI, L.M. História da formação de professores. Revista Brasileira de Educação. Rio de Janeiro, n. 14, maio/ago. 2000, p. 61-88.

UFFS. Diretoria de Organização Pedagógica. Chapecó, 2018a. Disponível em: <https://www.uffs.edu.br/institucional/pro-reitorias/graduacao/diretoria-de-organizacao-pedagogica>. Acesso em: 13 maio 2018.

UFFS. Núcleo de Apoio Pedagógico. Chapecó, 2018b. Disponível em: <https://www.uffs.edu.br/campi/chapeco/nucleo-de-apoio-pedagogico>. Acesso em: 09 mar. 2018.

UFFS. Plano de Desenvolvimento Institucional. Chapecó, 2019. Disponível em: <https://www.uffs.edu.br/institucional/a_uffs/a_instituicao/plano_de_desenvolvimento_institucional/pdi2019-2023/@@download/file>. Acesso em: 06 maio 2019. 
UFFS. Resolução $\mathbf{n}^{\mathbf{0}}$ 4/CONSUNI/UFFS/2015. Chapecó, 2015. Disponível em: <https://www.uffs.edu.br/atos-normativos/resolucao/consuni/2015-0004>. Acesso em: 15 ago. 2018.

VIEIRA, M.M.M.; ARAÚJO, M.C.P. Os estudos de Shulman sobre formação e profissionalização docente nas produções acadêmicas brasileiras. Revista Cadernos de Educação, Pelotas, n. 53, jan./abr. 2016, p. 80100.

VIEIRA, A.M.D.P.; GOMIDE, A.G. História da formação de professores no Brasil: o primado das influências externas. CONGRESSO NACIONAL DE EDUCAÇÃO - EDUCERE, 8, p. 3835-3848. Anais... Curitiba, 2008.

ZABALZA, M.A. O ensino universitário: seu cenário e seus protagonistas. Porto Alegre: Artmed, 2004.

\section{Correspondência}

Adriana Richit: Bolsista de Produtividade em Pesquisa do CNPq - Nível 2 (Pq - 2). Pós-doutorado em Didática da Matemática no Instituto de Educação da Universidade de Lisboa. Doutorado em Educação Matemática pela UNESP, Rio Claro, SP. Professora na Universidade Federal da Fronteira Sul - UFFS. Docente nos Programas de Pós-Graduação em Educação (PPGE) e Interdisciplinar em Ciências Humanas (PPGICH), ambos da UFFS. Coordenadora do Grupo de Estudos e Pesquisa em Educação Matemática e Tecnologias-GEPEM@T.

E-mail: adrianarichit@ gmail.com

Orcid: https://orcid.org/0000-0003-0778-8198

William de Almeida Xavier: Mestre em Educação pela Universidade Federal da Fronteira Sul. Servidor da Universidade do Estado de Santa Catarina (UDESC), Campus Chapecó. Membro do Grupo de Estudos e Pesquisa em Educação Matemática e Tecnologias (GEPEM@T).

E-mail: wxalmeida89@gmail.com

Orcid: https://orcid.org/0000-0001-5477-3373

Texto publicado em Currículo sem Fronteiras com autorização dos autores. 